\title{
Metformin Decreases Insulin Resistance in Type I Diabetes Through Regulating P53 and RAP2A in vitro and in vivo
}

This article was published in the following Dove Press journal: Drug Design, Development and Therapy

Gao-Fei Ren'
Li-Li Xiao'
Xiao-Jun Ma'
Yu-Shan Yan'
Peng-Fei Jiao'
'Department of Endocrinology, The First
Affiliated Hospital of Zhengzhou
University, Zhengzhou 450052, Henan
Province, People's Republic of China;
'Department of Cardiology, The First
Affiliated Hospital of Zhengzhou
University, Zhengzhou 450052, Henan
Province, People's Republic of China;
3Department of Respiratory, The First
Affiliated Hospital of Zhengzhou
University, Zhengzhou 450052, Henan
Province, People's Republic of China

Purpose: Patients with type 1 diabetes (T1D) a associated wis risk of multiple complications, so the development of T1D trea unt is $y$ ently needod. This study was set out to explore the molecular mechanism met $n$ in the eatment of T1D insulin resistance.

Patients and Methods: Subcutane $4 \mathrm{Sad}_{\mathrm{h}}$ e tissues wo collected from 68 T1D patients and 51 healthy controls. Insulin resistance moc rats and cells were constructed and treated with metformin respectively restern blot was use $o$ detect $\mathrm{p} 53$ and RAP2A protein levels, and qPCR was utilized to neasure p53 nd RAP2A mRNA levels. SiRNA and RAP2A siRNA vectors were constr ted to obser their effects on insulin resistance model cells. Results: In T1D p53 was regulat while RAP2A was down-regulated. Metformin could effectivel, the insum resistance and inflammatory response while downregulating p53 an ip-re 2 RAP2A. P53 induced insulin resistance and inflammatory respons inhibit AP2A and promoted apoptosis.

Cor asion Metfo in improves T1D insulin resistance and inflammatory response ugh $\mathrm{p} 5 \mathrm{R} \triangle \mathrm{P} 2 \mathrm{~A} \mathrm{p}$ hway, and the regulation of $\mathrm{p} 53 / \mathrm{RAP} 2 \mathrm{~A}$ pathway is conducive to imp the efficauy of metformin in the treatment of insulin resistance.

Keywo 's: type 1 diabetes, p53, RAP2A, insulin resistance, metformin
Correspondence: Peng-Fei Jiao Department of Respiratory, The First Affiliated Hospital of Zhengzhou University, No. I, Jianshe East Road, Zhengzhou 450052, Henan Province, People's Republic of China Tel +86 37I-669I3257 Email314761380@qq.com

\section{Introduction}

As one of the most common types of diabetes, ${ }^{1}$ type 1 diabetes (T1D) is a chronic immune disease caused by the erroneous work of pancreatic cells and the immune system, with the clinical manifestations of insulin deficiency and hyperglycemia. ${ }^{2}$ Untimely and inaccurate treatment of T1D will result in manifold complications in patients. For example, Hainsworth et $\mathrm{al}^{3}$ showed that T1D patients with hyperglycemia were highly likely to develop retinopathy. In addition, Gilsanz et $\mathrm{al}^{4}$ exhibited that T1D patients with depression were often accompanied by a high risk of dementia. While according to Chaytor et $\mathrm{al}^{5}{ }^{5}$ it was quite common for elderly patients with late T1D to suffer from cognitive impairment. At the same time, significantly elevated apolipoprotein C3 in T1D patients increased the risk of cardiovascular disease. ${ }^{6}$ Understanding the molecular mechanism of the occurrence of T1D, therefore, contributes greatly to the development of T1D therapy. Although there are increasing studies focusing on the pathogenesis of T1D, the molecular network of T1D remains elusive. 
The p53 protein encoded by the TP53 gene is a wellknown transcription factor that can regulate genes at the transcriptional level by suppressing the binding of other transcription factors to target sequences. ${ }^{7}$ It is well established that p53 protein is closely associated with cell metabolism. As reported by Lowman et $a{ }^{8}{ }^{8}$ p53 increased glutamate levels in mouse embryonic fibroblasts through Slc7a3/mTORC1, thereby promoting cell survival. In the study of Kim et al, ${ }^{9}$ wild-type p53 (WTp53) reduced pyruvate consumption in mitochondria by up-regulating PUMA, and accelerated anaerobic oxidation of sugars in cells. Moon et $\mathrm{al}^{10}$ confirmed that $\mathrm{p} 53$ inhibited tumor growth by suppressing the mevalonic acid pathway. It is worth mentioning that multiple studies ${ }^{11-15}$ have demonstrated that p53 is involved in insulin resistance, which means that p53 is closely related to diabetes. While RAP2A belongs to the RAS protein family. Abnormally expressed RAP2A is closely bound up with the occurrence of various cancers like gastric cancer, thyroid cancer, nasopharyngeal cancer, and liver cancer. ${ }^{16-19}$ Akt phosphorylation is an important part of the insulin delivery pathway, and RAP2A is closely linked to Akt phosphorylation, ${ }^{20}$ so it is highly possible that RAP2A may participate in the insulin pathway through Akt.

Metformin is a common insulin sensitizer. ${ }^{21}$ In th study, 3D3-L1 cells were induced by dexamethasone an mice were induced by high glucose and high construct insulin resistance models, and metfo in trea hent was performed on insulin model cells understand the molecular mechanisy of met. nin treatment of T1D insulin resistance ts relations with p53 and RAP2A.

\section{Patients and}

\section{TID Patients}

Subcutaneous apose ssue sa nl were collected from 68 T1D patier in the raftaffiliated Hospital of Zhengzhou University, inc g 42 males and 26 females, with a mean age of (54.14 \pm 8.2 - vears, a course of disease of (15.58 \pm 3.75$)$ years, a BMI of 21 . $\geq 0.74$ and an insulin sensitivity index (ISI) of $8.79 \pm 0.34$. In addition, another 51 healthy controls, including 29 males and 22 females, with an average age of (51.87 \pm 6.97$)$ years, a BMI of $18.25 \pm 0.63$ and an ISI of 11.41 \pm 0.27 were included as the control group. Inclusion criteria: Patients diagnosed with T1D and exhibiting insulin resistance. Exclusion criteria: Persons with mental illness; Patients with hypertension, kidney or coronary heart diseases; Patients with malignant tumors, acute inflammation or trauma.
Hyperinsulinemic-euglycemic clamp technique was employed to evaluate the degree of insulin resistance, and insulin resistance was judged by comparing the insulin sensitivity index of healthy controls and T1D patients. There were no statistically significant differences in age and gender between the two groups $(\mathrm{P}=0.116, \mathrm{P}=0.706)$, but there were statistical differences in BMI and ISI $(\mathrm{P}<0.001, \mathrm{P}<0.001)$. The study was approved by the Medical Ethics Committee of the First Affiliated Hospital of Zhengzhou University, and all the participants were informed of the whole process of the study and signed the informed consent. Subcutane-dipose tissues (2 g) were taken from the abdomen, re oved the arly visible blood vessels on the tissue block, an insed with st le normal saline before placing them in sterile a RNA-f EP tube. Then the tissue blocks y frozep in liq a rogen for 24 hours and stored in the ro oerat at $-80^{\circ} \mathrm{C}$ for later use. After the operation, the atients e close observed with antibacterial and a

\section{Establ-ment of sulin Resistance Model} The differentiation of 3 $13-\mathrm{L} 1$ cells (ATCC, USA) into ma re adipocy $s$ was induced using 3-isobutyl1-mo vlxanthin (MIBX) + dexamethasone + insulin. Then, 1 dexamethasone was applied to construct in resistance model cells, and the fluid was xchanged every $48 \mathrm{~h}$. The glucose consumption of the ulture medium was measured during the fluid xchange. When the glucose consumption was over 2.5 $\mathrm{mmol} / \mathrm{L}$, the cells were considered to be successfully developed insulin resistance. After that, the modeled cell adherents were inoculated in T25 culture flasks (Thermo Fisher Scientific) and cultured in an animal cell incubator (Binder, Germany) at $37^{\circ} \mathrm{C}$ and $5 \% \mathrm{CO}_{2}$. The culture medium was DMEM medium (Hyclone) + $10 \%$ fetal bovine serum solution (Gibco) $+1 \%$ penicillin/streptomycin solution (100X, Solarbio). Before transfecting the cells with expression vectors, the medium was changed to serum-free medium in advance. P53 siRNA, RAP2A siRNA, and NC siRNA were purchased from Shanghai Sangon Biotechnology Co., Ltd. Lipofectamine 2000 transfection kit (invitrogen, USA) was employed to transfect the cell line in accordance with the kit instructions. Fresh medium was replaced 8 $\mathrm{h}$ after transfection to avoid killing the cells.

Approved by the Medical Ethics Committee of the First Affiliated Hospital of Zhengzhou University, six week male rats (Hunan SJA Laboratory Animal Co., Ltd.) without obvious abnormal behavior and pathogen infection were 
selected. After one week of general feeding, the rats were fasted for 24 hours, and then injected intraperitoneally with alloxan. Seventy-two hours and 1 week later, the fasting blood glucose of rat tail tip was measured, and the diabetic model was successfully established when the blood glucose level was higher than that $16.7 \mathrm{mmol} / \mathrm{L}$ after two times of detection. The procedures were conducted in strict accordance with the guidelines for the Care and Use of Laboratory Animals (NIH publication, 1996 revision, No. 85-23). The tissue blocks were subcutaneous tissues collected from the abdomen of the rats, and the collection process was as follows: the rats were anesthetized with $2 \%$ pentobarbital sodium ( $40 \mathrm{mg} / \mathrm{kg}$ body weight) after preoperative fasting for 14 hours. An incision was then made in the middle of the rat abdomen to obtain subcutaneous tissue. The tissue blocks were frozen in liquid nitrogen for 24 hours and stored in the refrigerator at $-80{ }^{\circ} \mathrm{C}$ for testing.

\section{MTT Assay}

Four 96-well plates were selected, where the transfected cells were inoculated according to the specification of $2 \times 10^{3}$ per well, with 3 wells in each group. The cells were then cultured at $37{ }^{\circ} \mathrm{C}$ and $5 \% \mathrm{CO}_{2}$. One well plate was taken out every 24 hours, at which point 5 of MTT solution was added at $10 \mu \mathrm{L} /$ well, and the culture was then continued for 4 hours. the culture medium, $100 \mu \mathrm{L}$ (Solarbio Company) was added, $570 \mathrm{~nm}$ was measured by a ricropla reader. The experiment was repeated 3 to draw th cell viability-time curve.

\section{Glucose Ass?

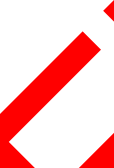

The insulin-resista

$(0.5-2.0 \mathrm{mr}, \mathrm{A} \rightarrow$ and $\mathrm{me}$ was replaced after 48 h. Gluc conte in the num was measured using the Glucose ssa constion was calcula.

\section{GTT and ITT for Glucose Tolerance and Insulin Sensitivity}

Metformin was added to the feed at a dose of $3 \times 10^{2} \mathrm{mg} / \mathrm{kg}$ body weight. Insulin tolerance test (ITT): Insulin-resistant rats were stopped from feeding for $12 \mathrm{~h}$, and their blood glucose index was detected, which was recorded as $\mathrm{T}=0$ $\mathrm{min}$. The rats were then intraperitoneally injected with insulin (dose: $0.5 \mathrm{U} / \mathrm{kg}$ ), and the fasting glucose of the rats was detected at 15, 30, 60, 90 and 120 min after the injection. Glucose tolerance test (GTT): After fasting the insulinresistant rats for $12 \mathrm{~h}$, their blood glucose index was detected and recorded as $\mathrm{T}=0 \mathrm{~min}$. The glucose (dose: $2 \mathrm{~g} / \mathrm{kg}$ body weight) was intraperitoneally injected into the abdominal cavity of the rats, and the fasting glucose was detected at 15, 30, 60, 90 and 120 min after the injection.

\section{qPCR}

Trizol method was utilized to extract total RNA from tissues or cells. The total OD of RNA at 260$280 \mathrm{~nm}$ was detected by $\mathrm{W}^{2}$ spectro otometer, and those with OD260/OD280> were sele for subsequent qPCR detectio Fast g One tep Reverse Transcription-Fluor cence Quant on Kit (Beijing Tiangen Corporau $F^{\circ}$ 14) and ABI PRISM 7000 (Applied Bio stems, sA) ins aments were employed to quantif VA levels. 2 RNA and RAP2A mRNA primers were vurchased from Shanghai Sangon Bi ology Co. td. The qPCR reaction system (50 L) was as follows: upstream primer $1.25 \mu \mathrm{L}$, downtream prim $1.25 \mu \mathrm{L}$, probe $1.0 \mu \mathrm{L}$, RNA template 10 A ug, 50 ROX Reference Dye ROX $5 \mu \mathrm{L}$, and RNás ddH2O was added to meet the total reaction rme of $50 \mu \mathrm{L}$. Reaction process: Reverse transcription at $50^{\circ} \mathrm{C}$ for $30 \mathrm{~min}$, one cycle; Predenaturation at $95^{\circ} \mathrm{C}$ for $3 \mathrm{~min}$, one cycle; Denaturation at $95^{\circ} \mathrm{C}$ for 15 $\mathrm{s}$, and annealing at $60^{\circ} \mathrm{C}$ for $30 \mathrm{~s}, 40$ cycles. The results were analyzed by ABI PRISM 7000 instrument. The internal reference gene was $\beta$-actin, and the data were standardized by $2{ }^{-\Delta \Delta \mathrm{Ct}}$ method.

\section{Western Blot}

First, the cells were rinsed with cold PBS for 3 times, added with a lysis buffer containing $20 \mathrm{mM}$ Tris- $\mathrm{HCl}$ solution (pH7.5, Solarbio company) and protein inhibitor (Solarbio company), and then carefully pipetted the solution so that the cells can be fully lyzed. Then, the solution was centrifuged at $1.6 \times 10^{4} \mathrm{xg}$ for $15 \mathrm{~min}$ at $4^{\circ}$ $\mathrm{C}$, and $50 \mu \mathrm{L}$ of the obtained supernatant was was processed for the determination of its protein concentration by BCA method. Next, $20 \mu \mathrm{g}$ of protein and equivalent molecular weight standards were loaded into SDS-PAGE gel wells, and electrophoresed at $100 \mathrm{~V}$ for $2 \mathrm{~h}$ to isolate the protein. Then, the separated protein was transferred to a nitrocellulose (NC) membrane and left at room temperature for $1 \mathrm{~h}$ (blocked with 5\% skimmed milk-PBS solution). The protein to be tested 
and $\beta$-actin primary antibody were then added and left to stand at $4{ }^{\circ} \mathrm{C}$ overnight. After that, the $\mathrm{NC}$ membrane was washed with PBS for three times, followed by the addition of goat anti-rabbit secondary antibody (HRP cross-linked), then continued to stand at room temperature for $1 \mathrm{~h}$. Finally, the NC membrane was washed with PBS solution and visualized using ECL chemiluminescence solution. The internal reference protein was $\beta$ actin, and the relative expression level of the protein to be tested = the gray value of the band to be tested/the gray value of the $\beta$-actin band. The proteins to be tested, as well as the $\beta$-actin primary and secondary antibody goat anti-rabbit (HRP cross-linked) were purchased from Abcam Company, Shanghai, China.

\section{Co-Immunoprecipitation}

The protein was extracted with the same method as mentioned in Western blot in the last paragraph. After washing twice with PBS buffer solution, 50\% Protein A/ $\mathrm{G}$ agarose resin was prepared with PBS buffer solution, and was added to the protein sample to eliminate nonspecific binding proteins. Followed by the addition of 5 $\mu \mathrm{g}$ p53 antibody and RAP2A antibody, and gently sho at $4^{\circ} \mathrm{C}$ overnight. After centrifugation at $1 \times 10^{3} \mathrm{~g}$ for min, the supernatant was discarded, and sample was repeated washing 4 times y $1 \mathrm{n}$. IP buffer. Western blot was used to iden prec proteins, with the same method as n Atione Western blot.

\section{Statistics and Anal ors}

Statistical analysis of ne coll led data was performed by SPSS 20.0 (Asia A 'cs Forr lly SPSS China), and the pis a nden s conducted using GraphPad rism 6). The c.periment was repeated three times. neasurcment data were expressed as Mean \pm SD. The rependent sample $t$ test was employed for statistical diff ences between TID patients and healthy controls, and insulin resistance rats model group and Metformin group. One-way ANOVA was applied to compare the statistical differences between insulin resistance cells in each group, and the post-hoc pair-wise comparison was performed by LSD- $t$ test. All data were double-tailed. With $95 \%$ as its confidence interval, a statistically significant difference was assumed at $\mathrm{P}<0.05$.

\section{Results}

\section{Metformin Improved Insulin Resistance}

3T3-L1 cells were induced by dexamethasone to construct an insulin resistance model, and insulin resistance model cells were treated with different concentrations of metformin $(0.5-2.0 \mathrm{nmol} / \mathrm{L})$. After $24 \mathrm{~h}$ of metformin treatment, the glucose content in the culture medium was detected using a glucose detection kit. When treated with metformin alone, it was observed that $0.5 \mathrm{nmol} / \mathrm{L}$ and $1.0 \mathrm{nmol} / \mathrm{L}$ of metformin promoted a small but not statistically significant increase in monsumption in insulin-resistant cells (Figur A). Who increased the metformin concentration to $5 \mathrm{nmol} / \mathrm{I}$ and 2.0 $\mathrm{nmol} / \mathrm{L}$, the glucose cor amption the groups was statistically high than $t^{2}$ of th nodel group, and $2.0 \mathrm{nmol} / \mathrm{L} \mathrm{m}$ fon in a the st effect on promoting cell gly ose cons ntion what's more, when metformin ad administe with insulin to cells (Figure 1B), 0.5 to $0 \mathrm{nmol} / \mathrm{L}$ metformin was found to dr atioally increaso glucose consumption in cells. It as worth mantioning that the increase of glucose con mption in he metformin + insulin groups was great than th in the metformin group, which sugthed that the combination of the two was more effecti in proving insulin resistance. Based on the effects of metformin on insulin-resistant cells, an insulin resisnce rats model was constructed to study the effect of metformin on the improvement of insulin resistance in vivo. The ITT and GTT results showed that after metformin treated insulin-resistant rats, the blood glucose levels of the rats decreased statistically at 15, 30, 60 , and 90 minutes (Figure $1 \mathrm{C}$ and D), and the effect of metformin combined with insulin was better than that of metformin, indicating that metformin could improve insulin resistance by promoting insulin absorption in model cells or rats.

\section{Metformin Down-Regulated p53 and Up-Regulated RAP2A}

Western blot and qPCR were employed to detect the differentially expressed genes in subcutaneous adipose tissues of 68 T1D patients and 51 healthy controls. The results demonstrated that $\mathrm{p} 53$ increased in adipose tissues of T1D patients while RAP2A decreased (Figure 2A). As shown in Figure 2B and C, p53 was up-regulated while RAP2A was down-regulated in adipose tissues and insulinresistant cells of insulin-resistant rats. After metformin 
A

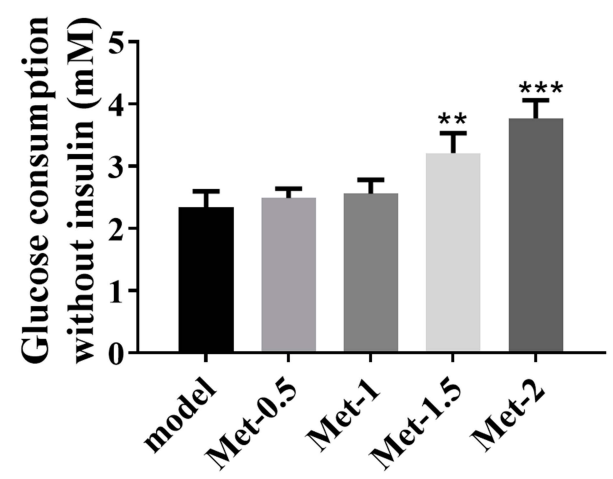

C

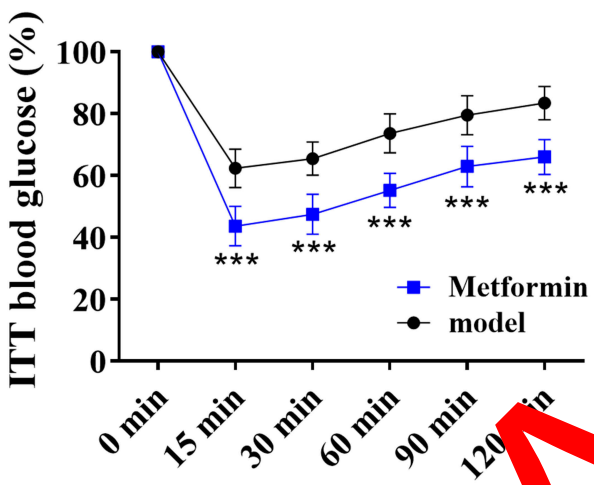

B

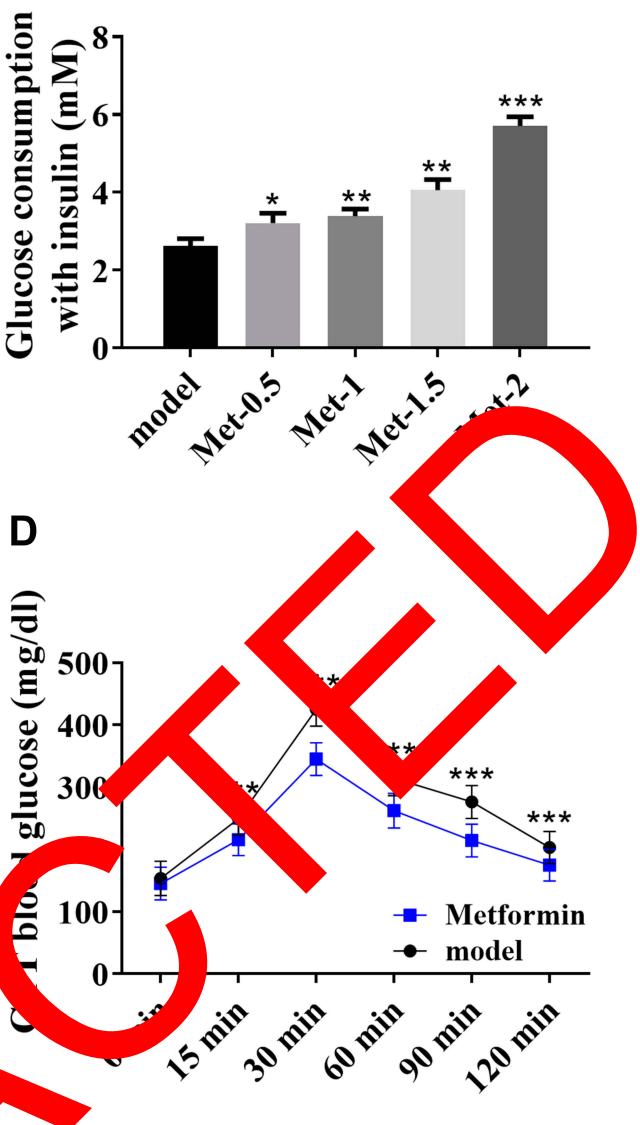

Figure I Metformin improved insulin resistance. (A) The absence of insulin. (B) In the presence of insulin, 0.5-2.0 o1/L me that of the group with metformin alone. (C) ITT re $s$ of insuli esistant ra *** Indicated $\mathrm{P}<0.001$ compared with the model group

treatment, whereas, p53 in cocreased and RAP2A increased. These resu suggested that metformin might improy nsulin resistan in T1D by regulating p53 and RA $(\mathrm{Fig} 2 \mathrm{D})$.

\section{Metfor $\mathrm{nn}_{\mathrm{n}}$ pro d/ sulin Resistance by Acti ting $1 /$ s/D-PIsK/Akt Pathway}

In the pro of insulin mediated glucose absorption, the IRS1/PI3K/A pathway was quite remarkable, so the disorder of this parrway was an important cause of insulin resistance. In this section, Western blot was used to detect IRS1, p-PI3K (PI3K phosphorylated) and p-Akt (Akt phosphorylated), and the effects of metformin on the insulin pathway was evaluated by the changes of the three. The results (Figure 3) exhibited that IRS1, p-PI3K, and p-Akt were down-regulated in adipose tissues and insulinresistant cells of insulin-resistant rats, while after metformin treatment, the expression levels of these three raised, indicating that metformin improved insulin resistance by activating the IRS1/p-PI3K/Akt pathway.

\section{Metformin Inhibited Apoptosis by Down-Regulating p53}

In view of the abnormal expression of p53 in T1D patients and insulin resistance model and the downregulation of p53 caused by metformin, we hypothesized that metformin might improve the symptoms of insulin resistance model by reducing the apoptosis caused by p53. Therefore, MTT was adopted to detect cell vitality, and Western blot to detect Caspase 3, Caspase 9, Bax and $\mathrm{Bcl} 2$ in insulin-resistant cells and rat adipose tissues. The results (Figure 4) demonstrated that in insulinresistant cells and rats, Caspase 3, Caspase 9 and Bax were up-regulated while $\mathrm{Bcl} 2$ was down-regulated. While the opposite results were observed after metformin treatment, that is, Caspase 3, Caspase 9 and Bax 
A
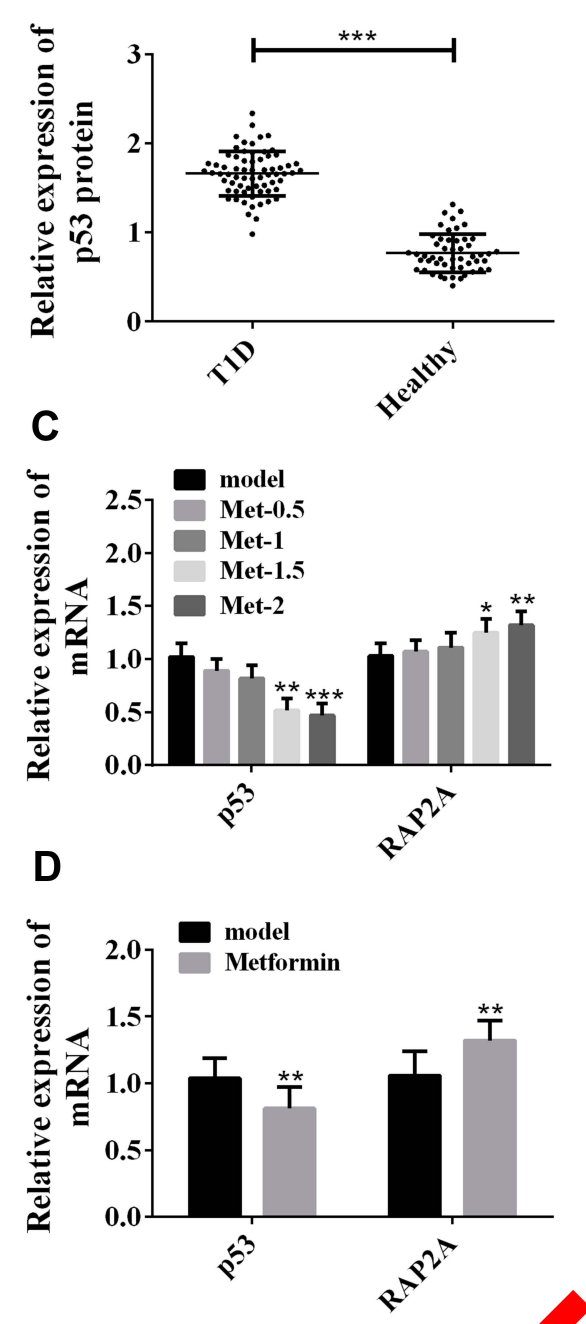

B
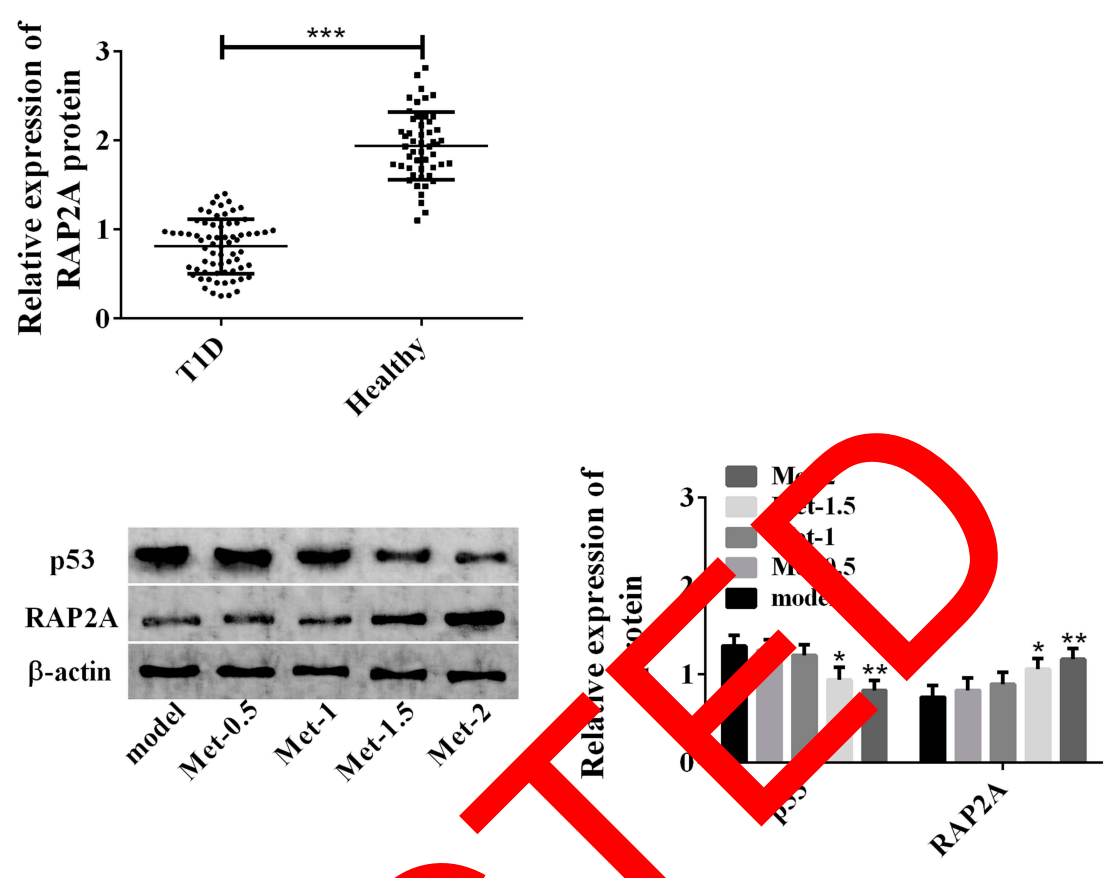

Figure 2 Metformin down-regulated $\mathrm{p} 53$ and ulated RAP2A. p53 was up-regulated in TID. ****Indicated P<0.00I. (B) RAP2A was down-regulated in TID. $* * *$ Indicated $\mathrm{P}<0.00 \mathrm{I}$. (C) Metformin down-r rated and up-regulat RAP2A in insulin-resistant cells. *Indicated $\mathrm{P}<0.05$, $* *$ Indicated $\mathrm{P}<0.0 \mathrm{I}$ and $* * *$ Indicated $\mathrm{P}<0.00 \mathrm{I}$ compared with the model group. (D) Metformin down vulated $\mathrm{p} 53$ and up-regulated RAP2A in insulin-resistant rats. $* *$ Indicated $\mathrm{P}<0.0 \mathrm{I}$, and $* * * I n d i c a t e d \mathrm{P}<0.00 \mathrm{I}$ compared with the model group.

were down-regulated w $\mathrm{Bcl} 2 \mathrm{~s}$ up-regulated. In addition, MTT esu show th metformin increased the viabili of ins in-resistar cells. All these results indicated tha $w$ cormm minited apoptosis and promoted cell viab/ by down-regulating p53.

\section{Metformin Improved the Inflammatory Response in Insulin Resistance Models} Inflammation is a common symptom of T1D, and the pathways involved in insulin resistance are closely related to inflammatory factors. As indicated above, metformin can activate the insulin pathway, so does metformin therefore regulate the inflammatory response in the insulin resistance model? In this part, the effects of metformin on the inflammatory response were eval-

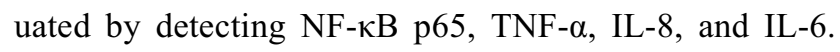
The results revealed that in insulin-resistant cells and rats, NF- $\kappa$ B p65, TNF- $\alpha$, IL-8, and IL-6 were all upregulated, while similarly, these indicators all elevated after metformin treatment, suggesting that metformin could improve the inflammatory response in insulin resistance models (Figure 5).

\section{p53 Induced Insulin Resistance by Inhibiting RAP2A}

In light of the aforementioned effects of metformin on insulin resistance, this section focused on discussing whether metformin could improve insulin resistance by 
A
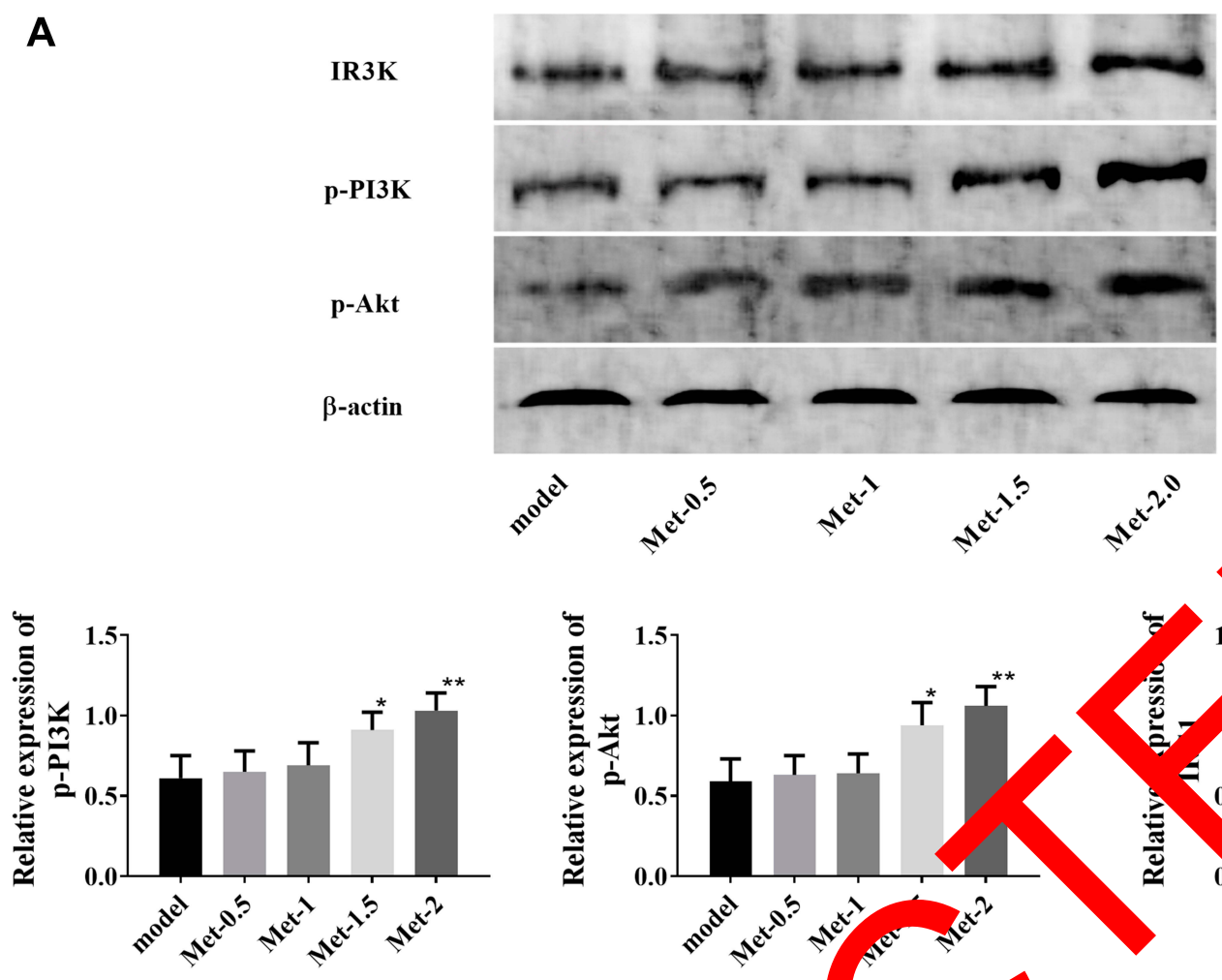

B
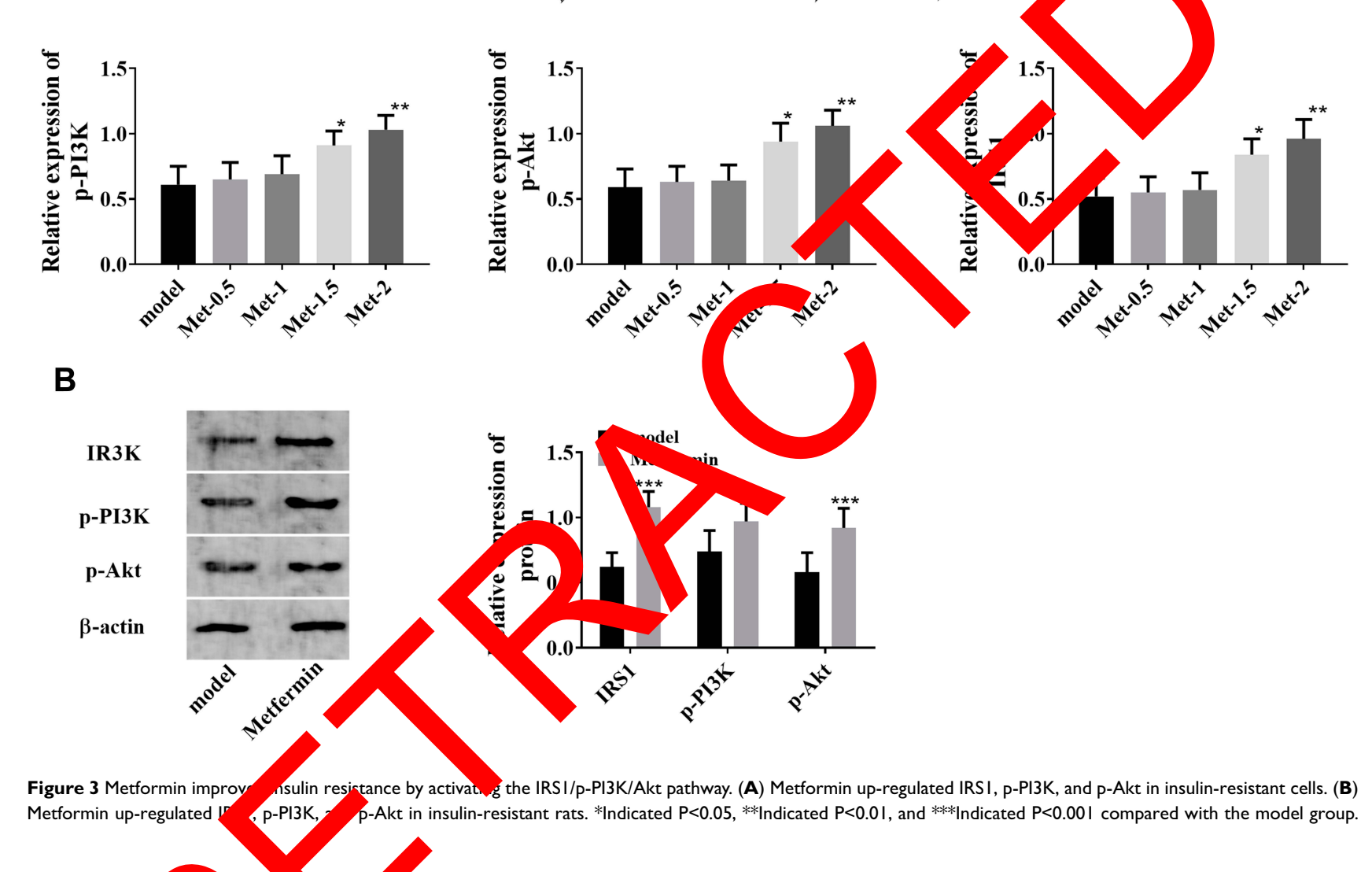

regulatin 553 d RA 253 siRNA and RAP2A siRNA ectors constructed to regulate p53 and RAP2A in din-resistant cells, and their effects on insulin resistance re studied. In was found that RAP2A was up-regulated whin p53 was down-regulated, suggesting that p53 might inhibit RAP2A in insulin-resistant cells (Figure 6A). In addition, when p53 was down-regulated, glucose consumption in insulin-resistant cells increased significantly, while inhibiting RAP2A could offset this increase in glucose consumption caused by p53 downregulation (Figure 6B), which indicated that $\mathrm{p} 53$ inhibited glucose consumption by down-regulating RAP2A. What's more, when cells were co-cultured with $1 \mathrm{nmol} / \mathrm{L}$ insulin, the glucose consumption increment caused by downregulation of p53 was significantly higher than that of the non-insulin group, suggesting that p53 inhibited insulin sensitivity by down-regulation of RAP2A. Moreover, as shown in Figure 6C-F, the decreased vitality, apoptosis, inflammatory response and IRS1/p-PI3K/p-Akt pathway disorders caused by down-regulation of $\mathrm{p} 53$ could all be offset by down-regulation of RAP2A.

The relationship between $\mathrm{p} 53$ and RAP2A was verified by CO-IP method. If $\mathrm{p} 53$ could interact with RAP2A, the p53 antibody would precipitate both p53 and RAP2A, and then RAP2A bands could be found when the precipitated protein was detected by Western blot. It was found that 


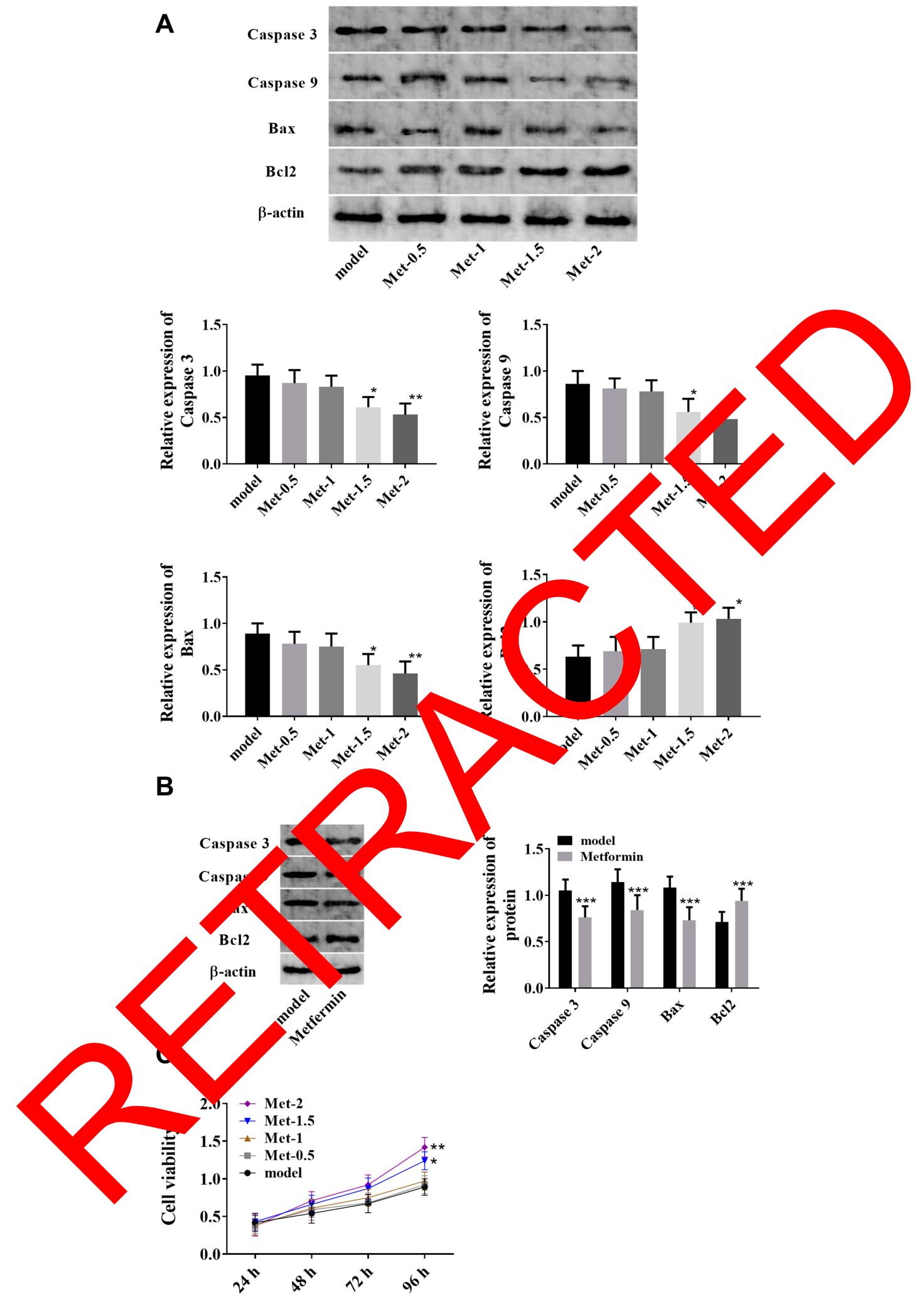

Figure 4 Metformin inhibited apoptosis by down-regulating p53. (A) Metformin down-regulated Caspase 3, Caspase 9, Bax, and up-regulates Bcl2 in insulin-resistant cells. (B) Metformin down-regulated Caspase 3, Caspase 9 and Bax, and up-regulated Bcl2 in insulin-resistant rats. (C) Metformin increased the viability of insulin-resistance cells. *Indicated $\mathrm{P}<0.05$, **Indicated $\mathrm{P}<0.01$, and $* * *$ Indicated $\mathrm{P}<0.00$ I compared with the model group. 


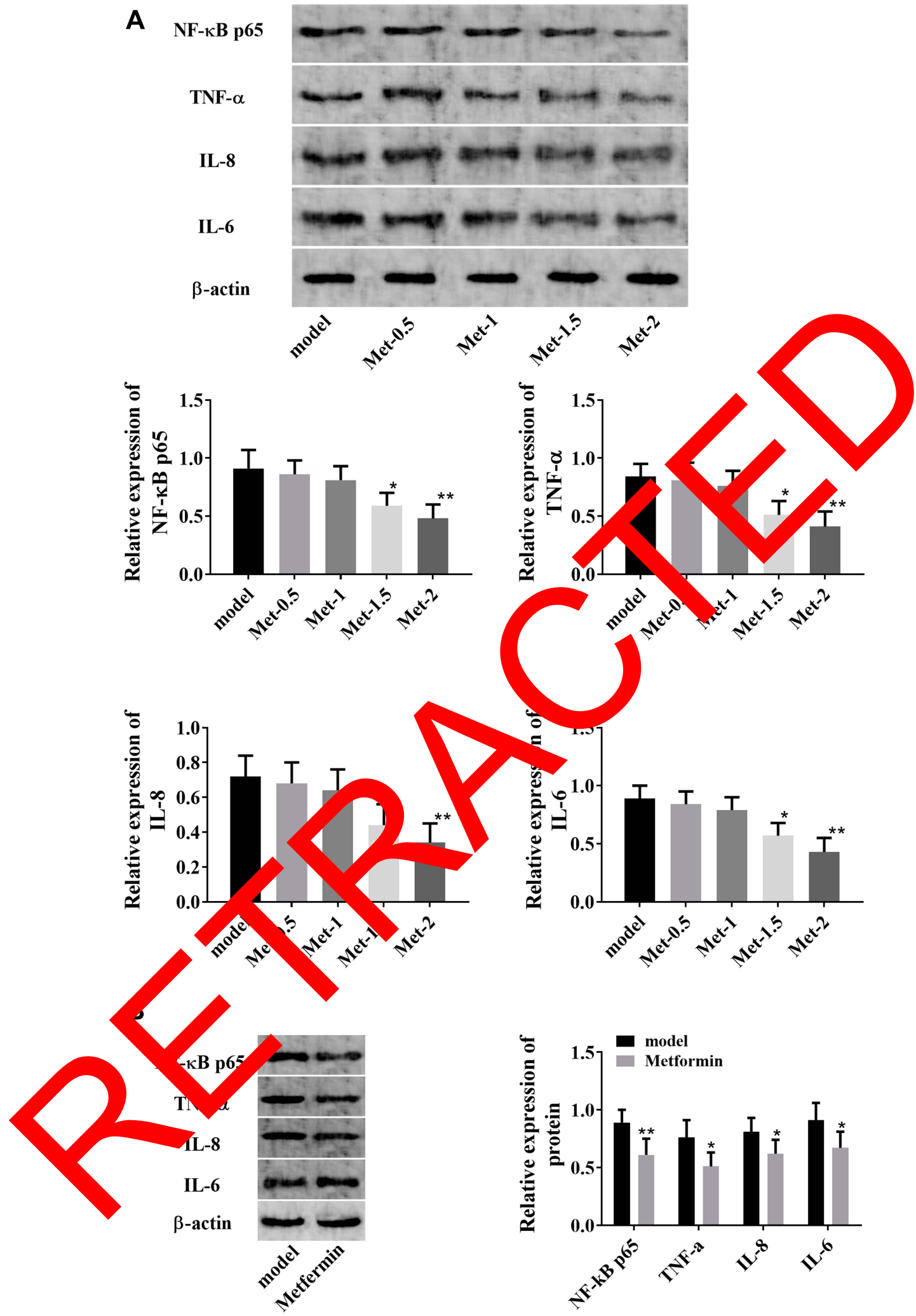

Figure 5 Metformin improved the inflammatory response in insulin resistance models. (A) Metformin down-regulated NF-kB p65, TNF- $\alpha$, IL-8 and IL-6 in insulin-resistant cells. (B) Metformin down-regulated NF-kB P65, TNF- $\alpha$, IL-8, and IL-6. *Indicated $\mathrm{P}<0.05$, and **Indicated $\mathrm{P}<0.01$ compared with the model group. 
A
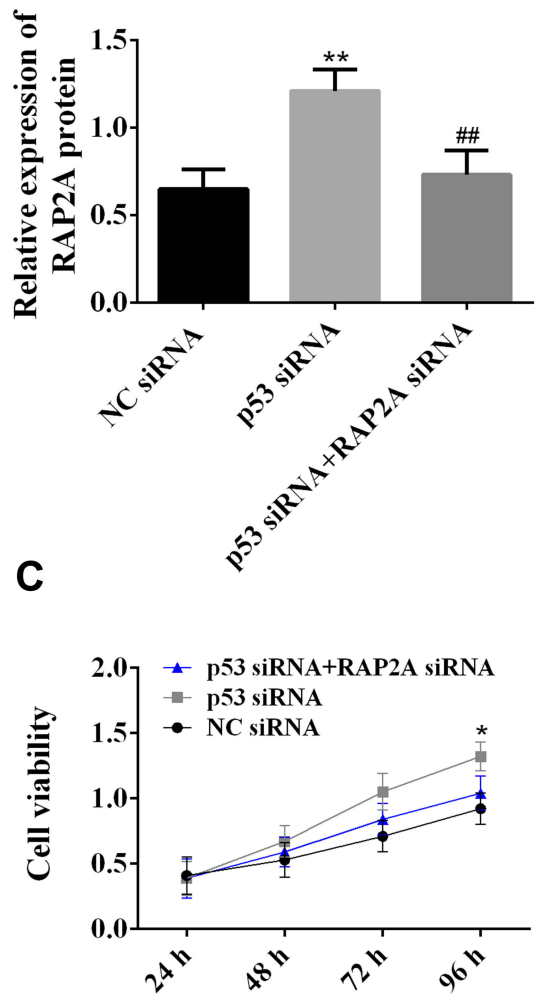

F

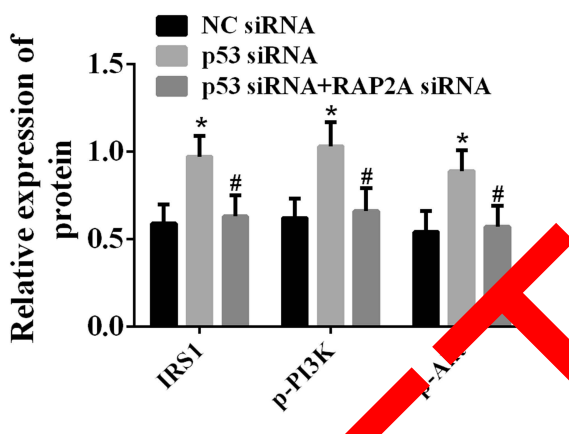

B

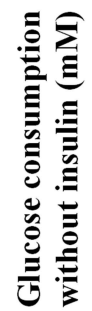

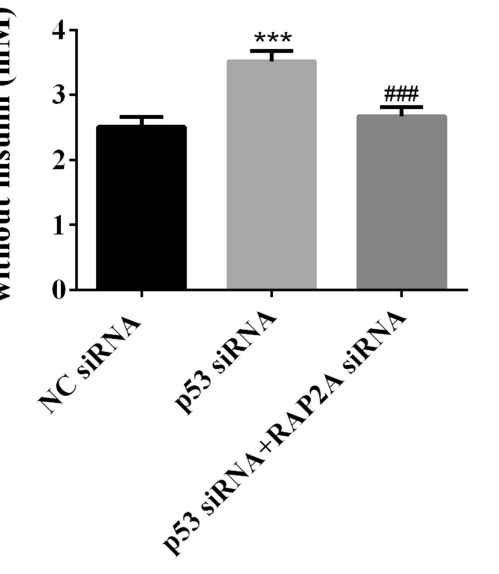

D
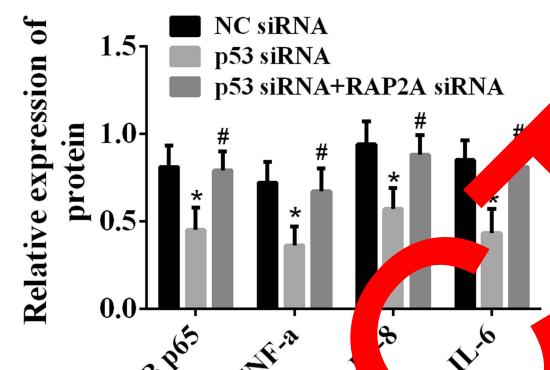

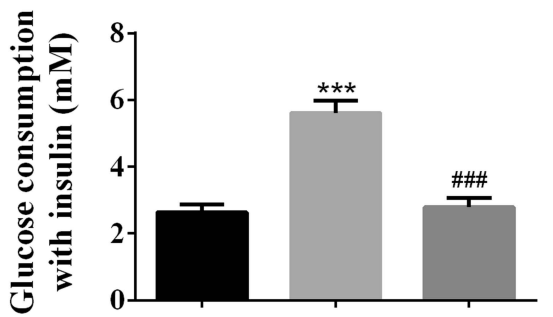

E

E

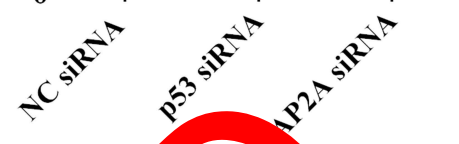

G

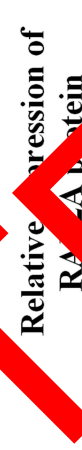

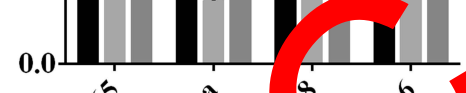

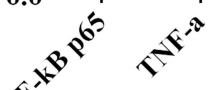

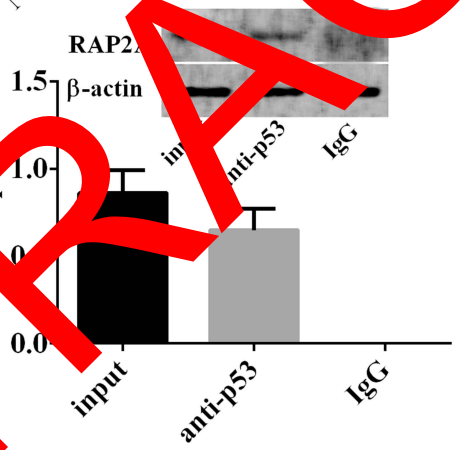

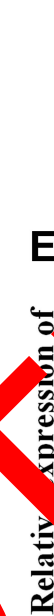
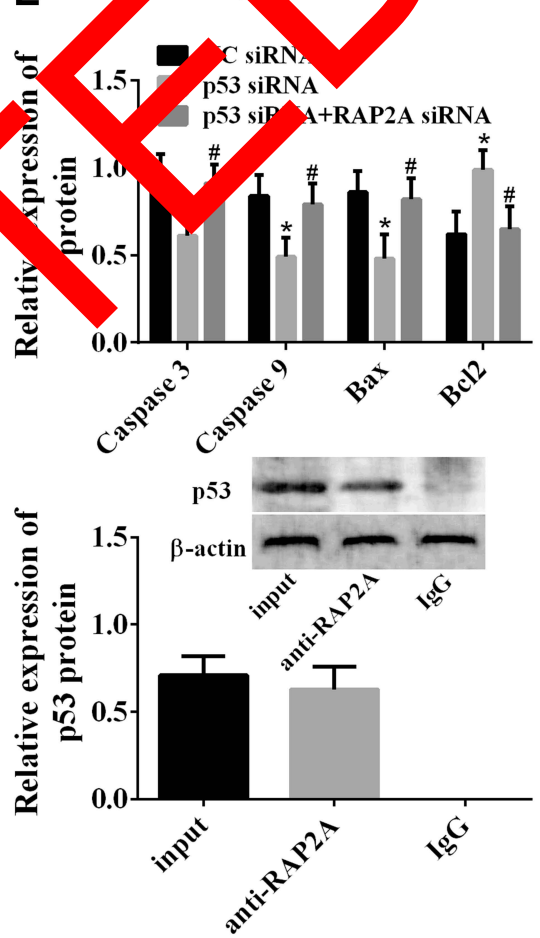

Figure 6 Metformin improved in

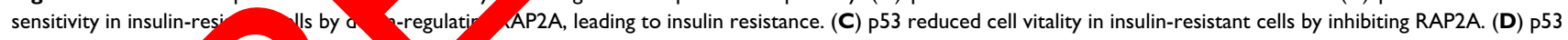
down-regulated NF NF- $\alpha, 8$, and $\mathrm{L}_{\mathrm{L}} \mathrm{n}$ in n-resistant cells by inhibiting RAP2A. (E) p53 down-regulated Caspase 3, Caspase 9, Bax and up-regulated Bcl2 in insulinresistant cells by Mbiting RA A. (F) p53 n-regulated IRSI, p-PI3K, and p-Akt in insulin-resistant cells by inhibiting RAP2A. (G) Co-immunoprecipitation confirmed

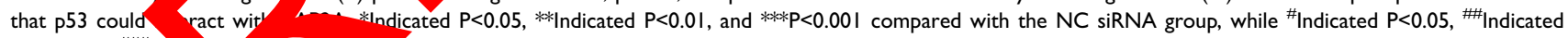
$\mathrm{P}<0.01$ and Ind 0.001 companed with $\mathrm{p} 53$ the siRNA group.

P53 could be precipuated with RAP2A antibody, and p53 bands were also obtained by subsequent Western blot detection of p53. All these demonstrated that p53 can bind to and interact with RAP2A (Figure 6G).

The above results indicated that $\mathrm{p} 53$ induced insulin resistance by inhibiting RAP2A, and metformin upregulated RAP2A by inhibiting p53, thereby activating the IRS1/p-PI3K/p-Akt pathway and inhibiting apoptosis and inflammatory responses.

\section{Discussion}

In present study, we found that p53 was up-regulated and RAP2A was down-regulated in subcutaneous tissue samples of T1D patients. Combined with the results of correlation analysis, we speculated that their abnormal expressions might be related to T1D insulin resistance. In addition, inhibition of p53 resulted in up-regulation of RAP2A, and co-immunoprecipitation indicated that p53 could interact 
with RAP2A, suggesting that p53 may regulate insulin resistance by inhibiting RAP2A. When studying the downstream of $\mathrm{p} 53, \mathrm{Wu}$ et $\mathrm{al}^{22}$ found that RAP2A was the downstream target of p53 in osteosarcoma cells, and p53 changed the downstream of MMP2, MMP9 and Akt by regulating RAP2A. The results of this study also confirmed that p53 could directly regulate RAP2A. It is particularly noteworthy that in the study of $\mathrm{Wu}$ et al, p53 up-regulated RAP2A, while in this study, p53 inhibited RAP2A, which may be due to the tissue-specific regulation of p53 on RAP2A.

The RAS protein family to which RAP2A belongs plays an indispensable role in the insulin pathway. In the insulin pathway, insulin binds to insulin receptors to drive Akt phosphorylation, a process based on RAS facilitation. ${ }^{23} \mathrm{Wu}$ et $\mathrm{al}^{20}$ also pointed out that RAP2A promoted Akt phosphorylation. In addition, Akt phosphorylation can inhibit apoptosis and inflammatory responses. ${ }^{24,25}$ Therefore, in current study, the up-regulation of RAP2A caused by the downregulation of $\mathrm{p} 53$ activated the downstream IRS1/PI3K/Akt pathway and inhibited the apoptosis pathway and inflammatory factors, which ultimately improved insulin resistance.

Metformin has a non-negligible role in T1D tre strategies. Long-term use of metformin may reduc possibility of cardiovascular disease in and metformin may be involved in the lin sensitivity in T1D patients. ${ }^{27,28}$ gulatic atient metformin was used to treat the isulin in stance model, it was found that metformin 1 use the dow regulation of p53 and the up-regulation of RA $\mathrm{A}$, accompanied by the activation of the $/ / \mathrm{p}-\mathrm{PI} 3 \mathrm{~K} / \mathrm{Akt}$ hway, the reduction of pro-inflap atory ctors, and the reduction of apoptosis. In comb $t_{i} /$ with $t^{1}>$ effects of metformin on p53 and A and re atory mechanism of p53/ RAP2A pathw?, we rothesized that metformin increase ins a serronty and promoted glucose consumption by hibiting the p53/RAP2A pathway.

This study . lored the molecular mechanism of metformin in the treatment of T1D insulin resistance and believed that metformin increased insulin sensitivity through the p53/RAP2A pathway. We found that p53 promoted insulin resistance by inhibiting RAP2A in adipose tissues, while p53 down-regulated insulin resistance as a suppressor in liver tissues, ${ }^{11}$ which indicated that p53 had two-sided effects on insulin. Besides, the regulation of p53 on RAP2A was also tissue-specific. Therefore, whether the p53/RAP2A pathway is tissue-specific can be further discussed in future experimental designs.

\section{Conclusion}

In summary, this study aims to explore the molecular mechanism of metformin in the treatment of T1D insulin resistance. It is found that metformin up-regulates RAP2A by inhibiting p53, and the up-regulated RAP2A induces the activation of downstream NF-B inflammation pathway, IRS1/PI3K/Akt pathway and apoptosis pathway, ultimately improving insulin resistance. The d. ism provides new therapeutic for for $\mathrm{P}$ insulin resistance-inhibition of p53 or up- ulation of $\mathrm{R}$ P2A can help improve the treatment $e^{c}$ ct of m sormin.

\section{Acknowledy ner s}

This study as suppo by ational Natural Science Foundati China (Gra o: 81400800) and the Key scientific resea projects of universities in Henan

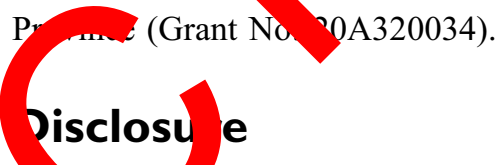

1. author eport no conflicts of interest in this work.

\section{nu arences}

1. Bullard KM, Cowie CC, Lessem SE, et al. Prevalence of diagnosed diabetes in adults by diabetes type - United States, 2016. MMWR Morb Mortal Wkly Rep. 2018;67(12):359-361. doi:10.15585/mmwr. mm6712a2

2. DiMeglio LA, Evans-Molina C, Oram RA. Type 1 diabetes. Lancet. 2018;391(10138):2449-2462. doi:10.1016/S0140-6736(18)31320-5

3. Hainsworth DP, Bebu I, Aiello LP, et al. Risk factors for retinopathy in type 1 diabetes: the DCCT/EDIC study. Diabetes Care. 2019;42 (5):875-882. doi:10.2337/dc18-2308

4. Gilsanz P, Schnaider Beeri M, Karter AJ, Quesenberry CP, Adams AS, Whitmer RA. Depression in type 1 diabetes and risk of dementia. Aging Ment Health. 2019;23(7):880-886. doi:10.1080/ 13607863.2018.1455167

5. Chaytor NS, Barbosa-Leiker C, Ryan CM, Germine LT, Hirsch IB, Weinstock RS. Clinically significant cognitive impairment in older adults with type 1 diabetes. J Diabetes Complications. 2019;33 (1):91-97. doi:10.1016/j.jdiacomp.2018.04.003

6. Kanter JE, Shao B, Kramer F, et al. Increased apolipoprotein C3 drives cardiovascular risk in type 1 diabetes. J Clin Invest. 2019;129 (10):4165-4179. doi:10.1172/JCI127308

7. Strycharz J, Drzewoski J, Szemraj J, Sliwinska A. Erratum to "is p53 involved in tissue-specific insulin resistance formation? Oxid Med Cell Longev. 2017;2017:8036902.

8. Lowman XH, Hanse EA, Yang Y, et al. p53 promotes cancer cell adaptation to glutamine deprivation by upregulating Slc7a3 to increase arginine uptake. Cell Rep. 2019;26(11):3051-3060 e3054. doi:10.1016/j.celrep.2019.02.037

9. Kim J, Yu L, Chen W, et al. Wild-type p53 promotes cancer metabolic switch by inducing PUMA-dependent suppression of oxidative phosphorylation. Cancer Cell. 2019;35(2):191-203 e198. doi:10.1016/j.ccell.2018.12.012 
10. Moon SH, Huang CH, Houlihan SL, et al. p53 represses the mevalonate pathway to mediate tumor suppression. Cell. 2019;176 (3):564-580 e519. doi:10.1016/j.cell.2018.11.011

11. Zhang X, Duan W, Lee WN, et al. Overexpression of p53 improves blood glucose control in an insulin resistant diabetic mouse model. Pancreas. 2016;45(7):1010-1017. doi:10.1097/MPA.0000000000000637

12. Nelson LE, Valentine RJ, Cacicedo JM, Gauthier MS, Ido Y, Ruderman NB. A novel inverse relationship between metformin-triggered AMPK-SIRT1 signaling and p53 protein abundance in high glucose-exposed HepG2 cells. Am J Physiol Cell Physiol. 2012;303(1):C4-C13. doi:10.1152/ajpcell.00296.2011

13. Shimizu I, Yoshida Y, Katsuno T, et al. p53-induced adipose tissue inflammation is critically involved in the development of insulin resistance in heart failure. Cell Metab. 2012;15(1):51-64. doi:10.1016/j.cmet.2011.12.006

14. Minamino T, Orimo M, Shimizu I, et al. A crucial role for adipose tissue p53 in the regulation of insulin resistance. Nat Med. 2009;15 (9):1082-1087. doi:10.1038/nm.2014

15. Tikoo K, Tripathi DN, Kabra DG, Sharma V, Gaikwad AB. Intermittent fasting prevents the progression of type I diabetic nephropathy in rats and changes the expression of Sir2 and p53. FEBS Lett. 2007;581 (5):1071-1078. doi:10.1016/j.febslet.2007.02.006

16. Wang L, Zhu B, Wang S, et al. Regulation of glioma migration and invasion via modification of Rap2a activity by the ubiquitin ligase Nedd4-1. Oncol Rep. 2017;37(5):2565-2574. doi:10.3892/ or.2017.5572

17. Lee YE, He HL, Chen TJ, et al. The prognostic impact of RAP2A expression in patients with early and locoregionally advanced nasopharyngeal carcinoma in an endemic area. Am J Transl Res. 2015;7 (5):912-921.

18. Prabakaran I, Grau JR, Lewis R, Fraker DL, Guvakova MA. Rap2A is upregulated in invasive cells dissected from follicular thyroid cancer. J Thyroid Res. 2011;2011:979840. doi:10.4061/2011/9798

19. Zheng X, Zhao W, Ji P, et al. High expression of Rap2A is associat with poor prognosis of patients with hepatocellular carcinoma Int J Clin Exp Pathol. 2017;10(9):9607-9613.
20. Wu JX, Du WQ, Wang XC, et al. Rap2a serves as a potential prognostic indicator of renal cell carcinoma and promotes its migration and invasion through up-regulating p-Akt. Sci Rep. 2017;7(1):6623. doi:10.1038/s41598-017-06162-7

21. Giannarelli R, Aragona M, Coppelli A, Del Prato S. Reducing insulin resistance with metformin: the evidence today. Diabetes \& Metabolism. 2003;29(4):6S28-35. doi:10.1016/S1262-3636(03)72785-2

22. Wu JX, Zhang DG, Zheng JN, Pei DS. Rap2a is a novel target gene of p53 and regulates cancer cell migration and invasion. Cell Signal. 2015;27(6):1198-1207. doi:10.1016/j.cellsig.2015.02.026

23. Molinaro A, Becattini B, Mazzoli A, et al. Insulin-driven PI3K-AKT signaling in the hepatocyte is mediated by redundant PI3K $\alpha$ and PI3K $\beta$ activities and is promoted by RAS. Cell Metab. 2019;29 (6):1400-1409 e1405. doi:10.1016/j.cmet.2019.03.010

24. Carvalho BC, Oliveira LC, Rocha CD, et knock-down and overexpression of Rap2a small GTPa in macro ges result in impairment of NF- $\mathrm{KB}$ activity and ammatory ge expression. Mol Immunol. 2019;109:27-37. Noi:10. 6/j.molimm. 19.02.015

25. Zhao Y, Song W, Wang Z, al. Resvo ol atten es testicular apoptosis in type 1 diabeti nice: role of Ak ed d Nrf2 activation and p62-depen Kear degrada, Redox Biol. 2018;14:609-617. d $>10$. 6/i dox.2017. 007

26. Petrie JR, Chatur $\mathrm{N}$, For et al. C covascular and metabolic effects of metf in in patients ty 1 diabetes (REMOVAL): a double-blin rand sed, placebo- Atrolled trial. Lancet Diabetes Endocrinol. 2017;5(8) _ 609. doi:10.1016/S2213-8587(17)30194-8

27. Bjor Schafer M, ong U, et al. Metformin improves insulin itivity and vascular heam in youth with type 1 diabetes mellitus. culation. 2018;138(25):2895-2907. doi:10.1161/ RCULATIONA A.118.035525

28. C Green $\mathrm{M}, \mathrm{J}$ gman BC, Cengiz E, et al. Metformin improves perip 1 in sensitivity in youth with type 1 diabetes. $J$ Clin Endocrinol Metab. 2019;104(8):3265-3278. doi:10.1210/jc.2019-

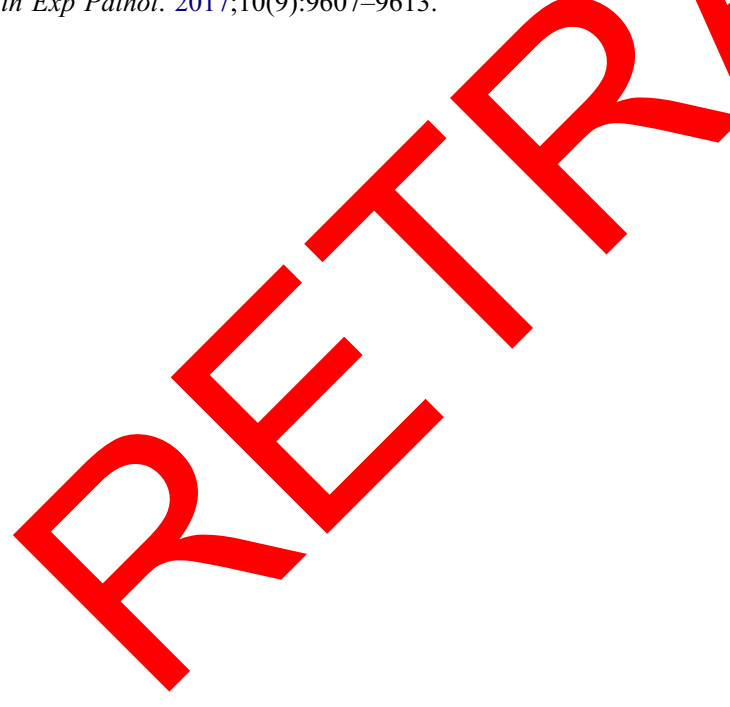

Drug Design, Development and Therapy

Dovepress

\section{Publish your work in this journal}

Drug Design, Development and Therapy is an international, peerreviewed open-access journal that spans the spectrum of drug design and development through to clinical applications. Clinical outcomes, patient safety, and programs for the development and effective, safe, and sustained use of medicines are a feature of the journal, which has also been accepted for indexing on PubMed Central. The manuscript management system is completely online and includes a very quick and fair peer-review system, which is all easy to use. Visit http://www. dovepress.com/testimonials.php to read real quotes from published authors. 